\title{
OBESE PRIMIGRAVID WOMEN;
}

FREQUENCY OF MACROSOMIA

1. FCPS-II Resident

Department of Obstetrics and Gynecology unit- IV Liaquat

University of Medical and Health Sciences (LUMHS), Jamshoro, Pakistan.

2. DMRD

Department of Radiology Liaquat University of Medical and Health Sciences (LUMHS), Jamshoro, Pakistan.

3. FCPS

Head of Department

Obstetrics and Gynecology unit- IV, Liaquat University of Medical and Health Sciences (LUMHS) Jamshoro, Pakistan.

4. FCPS

Associate Professor Department Obstetrics and Gynecology unitIV Liaquat University of Medical and Health Sciences (LUMHS), Jamshoro, Pakistan.

5. FCPS

Associate Professor Department of Obstetrics and Gynecology unit- IV Liaquat University of Medical and Health Sciences (LUMHS), Jamshoro, Pakistan.

\section{Correspondence Address:} Dr. Syed Zulfiquar Ali Shah

House No: 279 Doctor's Colony Hirabad, Hyderabad, Sindh.

zulfikar229@hotmail.com

Article received on:

21/10/2016

Accepted for publication:

15/05/2017

Received after proof reading: 08/08/2017

\section{INTRODUCTION}

The pre pregnancy BMI is a major predictor of birth weight with maternal obesity having an increased rate for delivering large for date babies. ${ }^{1}$ Former studies had reported that the obese mother is 1.4-18 times more likely to give birth to a large for date infant. ${ }^{2,3}$ Macrosomia (babies with an excessive birth weight) leads to the risk of brain injury, shoulder dystocia, low apgar scores and perinatal death. ${ }^{4} \mathrm{~A}$ study examined the mode of delivery of infants weighing $>4 \mathrm{~kg}$ shown the incidence of $\mathrm{C}$-section among the macrosomic babies was $25.8 \%$ as compared with $13.1 \%$ in general population. ${ }^{5}$ The reported incidence for shoulder dystocia was $7.6 \%$ which can leads to Erb's palsy common complication with macrosomic babies. ${ }^{6}$ The babies born to obese mothers needs more admissions to neonatal intensive care (NICU) unit for proper evaluation, monitoring and management. ${ }^{7}$ In a study conducted in France, the frequency of infants need admission in a NICU was 3.5 times higher in obese mothers. ${ }^{8}$ Maternal obesity has increased risk for stillbirth and neonatal death as compared to normal weight mothers. The stillbirths is due to intrauterine death and impairment of fetoplacental process among obese pregnant women as compared with normal weight ladies. ${ }^{9}$ Excessive growth of the fetus is a main contributor to adverse obstetrical outcomes ${ }^{10}$, 
Khashu et al. examined the perinatal outcomes of 1842 macrosomic newborns in British Columbia, and Canada and observed significantly increased maternal risks of emergency Caesarean section, postpartum hemorrhage, obstetrical trauma and maternal diabetes. ${ }^{11}$

Maternal obesity contributes to macrosomia via mechanisms including increased insulin resistance resulting in increase fetal insulin and glucose levels. ${ }^{12}$ Placental lipases metabolize triglycerides in maternal blood, allowing free fatty acids to be transferred in excess to the growing fetus. ${ }^{13}$ Factors associated with fetal macrosomia include duration of gestation, genetics, diabetes mellitus and existence of gestational diabetes. Genetic, ethnic, racial factors influence birth weight and the risk of macrosomia. ${ }^{14}$

Therefore, by considering such theme in mind the present study was conducted in the department of gynecology and obstetrics at Liaquat University Hospital Jamshoro. The study will explore the frequency of macrosomia in obese primigravid women so the proper workup and management strategies can be planned according to the results of the present study.

\section{PATIENTS AND METHODS}

This case series study of six months was conducted in the department of gynecology and obstetrics department Jamshoro. The inclusion criteria of the study were primigravida women between age 18 to 35 years with singleton pregnancy and gestational duration of 37 to 42 weeks, and during labour with BMI 30 or $>30 \mathrm{~kg} / \mathrm{m}^{2}$ and All booked women who were primigravid during antenatal visit try to come and BMl calculated by weight in $\mathrm{kg}$ and height in meter square while exclusion criteria were obese multigravid women and pregnant women with diabetes mellitus, hypertension or any other chronic metabolic or infectious disease. The macrosomic infants were considered when infant weight more than $4.5 \mathrm{~kg}$ at birth. The informed consent was taken while the data was collected on pre-designed proforma. The variables include post-delivery if the weight of baby is $4.5 \mathrm{~kg}$ is macrosomic and mode of the delivery. The data was analyzed in SPSS version 17, the frequency and percentage was calculated, effect modifier like age, gestational age, and BMI was entered and addressed by stratifications while the chisquare test was applied on categorical variables and the $p$-value $\leq 0.05$ was considered as significant.

\section{RESULTS}

During six months study period total 203 pregnant obese ladies were observed for macrosomic babies. Age group was analyzed which shows that in age group between 18-25 years were $105(52.00 \%)$ women, in age group of $26-30$ years were $62(30.69 \%)$ women and age group of 30 years and above were 35 (17.31\%) women with mean age \pm SD of ladies was $24.6 \pm 6.2$ years. Regarding modes of delivery shown 132 (65.02\%) ladies had C-section and 71 (34.97\%) ladies had vaginally delivery. Weight of the babies was assessed which shows 27 (13\%) were born with less than $2.5 \mathrm{Kg}$, babies having weight between $2.6-3 \mathrm{Kg}$ were 71 (35.3\%), babies were having weight $3 \mathrm{~kg}$ to $4.5 \mathrm{~kg} 38(18.7 \%)$ and babies having more than $4.5 \mathrm{~kg}$ which shows 67 (33\%) shown in Table-I. Neonatal complications observed were macrosomic babies 67 (33.1\%). Frequency of macrosomic babies was higher in women with BMI more than $3.5 \mathrm{~kg} / \mathrm{m}^{2} 44(21.67 \%)$ and in women with BMI between 30 to $35 \mathrm{~kg} /$ $\mathrm{m}^{2}$ 25(12.31\%). The macrosomic complication, with regards to age group in 18 to 25 years 31 , 25 to 30 years 19 , and more than 30 years 17 . $\mathrm{C}$-section complication with regards to age group is 57 in 18 to 25 years, 34 were 25 to 30 years, and 41 in more than 30 years. Macrosomic with regards to gestational age is 11 in 18 to 25 years, 12 between 25 to 30 years and 8 if more than 30 years. C-section complication with regarding to gestational age is 35 in 18 to 25,51 were in 25 to 30 years and 46 were in age more than 30 years. The stratification of complications regarding BMI, maternal and gestational age are mentioned in Table-II-IV. 


\begin{tabular}{|l|c|c|}
\hline Weight of Baby (KG) & Frequency & Percent \\
\hline$\leq 2.5$ & 27 & 13 \\
\hline $2.5-3$ & 71 & 35.3 \\
\hline $3.00-4.5$ & 38 & 18.7 \\
\hline Macrosomic $>4.5$ & 67 & 33 \\
\hline Total & 203 & 100 \\
\hline \multicolumn{2}{|c|}{ Table-l. Weight of new born baby } \\
\hline
\end{tabular}

\begin{tabular}{|c|c|c|c|c|}
\hline $\begin{array}{l}\text { Compli- } \\
\text { cations }\end{array}$ & Total & $\begin{array}{c}\text { BMI (30- } \\
35 \mathrm{Kg} / \mathrm{m}^{2} \\
\mathrm{n}(\%)\end{array}$ & $\begin{array}{c}\text { BMI } \\
(\geq 35 \mathrm{Kg} / \\
\left.\mathrm{m}^{2}\right) \mathrm{n}(\%)\end{array}$ & $\begin{array}{l}P \text { - } \\
\text { value }\end{array}$ \\
\hline C-Section & $\begin{array}{c}132 \\
(65.02 \%)\end{array}$ & $60(29.7)$ & $72(35.46)$ & 0.041 \\
\hline NVD & $\begin{array}{c}71 \\
(34.97 \%)\end{array}$ & $26(12.8)$ & $45(22.1)$ & 0.003 \\
\hline Macrosomic & 67 (33.1) & $25(12.5)$ & $44(21.67)$ & 0.032 \\
\hline
\end{tabular}

Table-II. Stratification of variables with regard to BMI

\begin{tabular}{|l|c|c|c|c|}
\hline \multicolumn{9}{|c|}{ Age Groups (years) } \\
\hline Complications & $\mathbf{1 8 - 2 5}$ & $\mathbf{2 5 - 3 0}$ & $\mathbf{>} \mathbf{3 0}$ & P-value \\
\hline C-Section & 57 & 34 & 41 & 0.07 \\
\hline Macrosomic & 31 & 19 & 17 & 0.041 \\
\hline
\end{tabular}

Table-III. Stratification of variables with regard to age group

\begin{tabular}{|l|c|c|c|c|}
\hline & \multicolumn{4}{|c|}{ Gestational age (weeks) } \\
\hline Complications & 18 to 25 & $25-30$ & $>30$ & P-value \\
\hline C-Section & 35 & 51 & 46 & 0.063 \\
\hline Macrosomic & 11 & 12 & 8 & 0.025 \\
\hline
\end{tabular}

Table-IV. Stratification of variables with regard to gestational age

\section{DISCUSSION}

In comparison to Sridhar SB, etal ${ }^{15}$ neonatal outcomes on gestational weight gain in morbidly obese $(\mathrm{BMI} \geq 40.00)$ ladies, this study shown that $30.6 \%$ of ladies gained the recommended amount of weight during pregnancy while $52.3 \%$ of ladies gained more than recommendations whereas $17.1 \%$ acquired less than recommended. In ladies with normal pre-pregnancy weight, excess weight associated with risk for increase duration of labour, pregnancy induced hypertension and birth weight $\geq 4000 \mathrm{~g}$ as obesity is associated with increased risk for hypertension and birth weight. Obstetric and perinatal outcomes were also studied, the obese women are at risk for preeclampsia and gestational diabetes mellitus and in such subjects the rate of caesarean section rate is high. It has also been reported that the rate of in-utero fetal death, neonatal mortality was significantly higher in the obese women and the high $\mathrm{BMI}$ also a predictor for gestational diabetes and eclampsia. Many theories has been stated regarding the association of pre-eclampsia and dyslipidemia (weight gain), abnormality in prostaglandin functions causes arteriolar constriction and are responsible for in-utero fetal deaths in obese women, also probably due to placental dysfunction related to weight gain itself. It has been observed that the dyslipidemia in obesity increases peroxidase formation, leads to vasoconstriction and aggregation of platelet and thus impairs perfusion for placenta. Babies of obese mothers are most likely to be large for gestational age (LGA) and macrosomic in comparison to normal weight pregnant ladies. The higher rate in this study might be due to quality of study population and this is tertiary care public governmental hospital received the referral cases from urban as well remote peripheral areas of province in emergency. In present study the macrosomia was observed in $33 \%$ babies while in the study by Gaudet L, et $\mathrm{al}^{2}$ it was $22.4 \%$ and majority of the ladies underwent $\mathrm{C}$-section while in the Saudi Arabian study prevalence of fetal macrosomia was $4.5 \% .{ }^{16}$ The macrosomia was mostly observed in mothers of 30+ age had 2530 weeks of gestation with statistical significant and the findings are also consistent with the study by Leddy MA, et al respectively. ${ }^{17}$

The result was comparable with the study conducted by Ehrenberg et al. in 2004 in Ohio, US, that found that the prevalence of macrosomia was $11.8 \%$ of population sample. ${ }^{18}$ The incidence of macrosomia also was confirmed to be approximately $7 \%-10 \% .^{19}$ The newborns that were $4.5 \mathrm{~kg}$ or heavier constituted $1-2 \%$ of all of the newborns. ${ }^{20}$ The incidence of macrosomia was reported as $9.8 \%$ in a study conducted in Turkey. ${ }^{21}$ However, the rate was determined as $5.8 \%$ in the study by Hajy-Ebrahim-Tehrani et al. in Iran. ${ }^{22}$ There are many studies reporting that the history of a pervious macrosomic baby is the most common leading maternal factor to macrosomia. 23,24 
No intervention has been proven to reduce the macrosomic risk, although several useful strategies are supportive including strict glycemic control during pregnancy by diet and insulin, prevention of maternal obesity during pregnancy and the rate of perinatal and maternal morbidity can be reduced by antenatal diagnosis. ${ }^{25}$ The risk factors for macrosomia should be thoroughly assessed by the clinician because majority of factors are preventable, and with good cooperation of gynecologists, pediatricians and dieticians along with maternal training and counseling, the number of such incidences can be minimized. ${ }^{26}$

\section{CONCLUSION}

Obesity is responsible for complications during pregnancy and delivery for both mother and babies. Fetal complications are macrosomia and these obese ladies should be motivated for weight loss and maintenance and taking preventive measures for excessive weight gain during pregnancy. Such plan leads to decreases in complication rate and this strategy should begin during preconception period.

Copyright@ 15 May, 2017.

\section{REFERENCES}

1. Sridhar SB, Ferrara A, Ehrlich SF, Brown SD, Hedderson MM. Risk of large-for-gestational-age newborns in women with gestational diabetes by race and ethnicity and body mass index categories. Obstet Gynecol.2013; 121(6):1255-62.

2. Gaudet L, Ferraro ZM, Wen SW, Walker M. Maternal obesity and occurrence of fetal macrosomia: a systematic review and meta-analysis. Biomed Res Int. 2014; 2014:64-9.

3. Najafian $M$, Cheraghi $M$. Occurrence of Fetal Macrosomia Rate and Its Maternal and Neonatal Complications: A 5-Year Cohort Study. ISRN Obstet Gynecol.2012; 2012:35-40.

4. Mohammadbeigi A, Farhadifar F, Zadeh NS, Mohammadsalehi N, Rezaiee M, Aghaei M. Fetal Macrosomia: Risk Factors, Maternal, and Perinatal Outcome. Ann Med Health Sci Res.2013; 3(4):546-550.

5. Conway DL. Delivery of the macrosomic infant: cesarean section versus vaginal delivery. Semin Perinatol. 2002; 26(3):225-31.
6. Ceriani-Cernadas JM, Mariani G, Pardo A, Aguirre A, Perez $C$, Brener $P$, et al. Cesarean delivery at term in low risk pregnancies: effects on neonatal morbidity. Arch Argent Pediatr 2010; 108:17-23.

7. Young BC, Ecker JL. Fetal macrosomia and shoulder dystocia in women with gestational diabetes: risks amenable to treatment? Curr Diab Rep. 2013; 13(1):128.

8. Batallan A, Goffinet F, Paris-Llado J, Fortin A, Breart G, Madelenat $P$, et al. Fetal macrosomia: management, obstetrical and neonatal results. Multicenter casecontrol study in $\mathbf{1 5}$ maternity hospitals in Paris and the Ile de France area. Gynecol Obstet Fertil. 2002; 30(6):483-91.

9. Nielsen LF, Schendel D, Grove J, Hvidtjorn D, Jacobsson $\mathrm{B}$, Josiassen $\mathrm{T}$, et al. Asphyxia-related risk factors and their timing in spastic cerebral palsy. BJOG 2008; 115:1518-28.

10. Bogaerts A, Ameye L, Martens E, Devlieger R. Weight loss in obese pregnant women and risk for adverse perinatal outcomes. Obstet Gynecol. 2015; 125(3):56675.

11. Khashu M, Pelligra G, Bhargava S, Smyth JA. Perinatal Morbidity in Macrosomic Infants. Pediatric Academy of Sciences.2005:12-18.

12. Gaillard R. Maternal obesity during pregnancy and cardiovascular development and disease in the offspring. Eur J Epidemiol. 2015; 30:1141-52.

13. Penfold NC, Ozanne SE. Developmental programming by maternal obesity in 2015: Outcomes, mechanisms, and potential interventions. Horm Behav. 2015; 76:143-52.

14. Bodnar LM, Siminerio LL, Himes KP, Hutcheon JA, Lash TL, Parisi SM, et al. Maternal obesity and gestational weight gain are risk factors for infant death. Obesity (Silver Spring).2016; 24(2):490-8.

15. Sridhar SB, Xu F, Hedderson MM. Trimester-specific gestational weight gain and infant size for gestational age. PLoS One.2016; 11(7):1595-99.

16. Alsammani MA, Ahmed SR. Fetal and Maternal Outcomes in Pregnancies Complicated with Fetal Macrosomia. N Am J Med Sci. 2012; 4(6):283-86.

17. Leddy MA, Power ML, Schulkin J. The Impact of Maternal Obesity on Maternal and Fetal Health. Rev Obstet Gynecol. 2008 Fall; 1(4):170-78.

18. Ehrenberg HM, Mercer BM, Catalano PM. The influence of obesity and diabetes on the prevalence 
of macrosomia. American Journal of Obstetrics and Gynecology. 2004; 191(3):964-68.

19. Olokor OE, Onakewhor JU, Aderoba AK. Determinants and outcome of fetal macrosomia in a Nigerian tertiary hospital. Niger Med J.2015; 56(6):411-5.

20. Boyd ME, Usher RH, McLean FH. Fetal macrosomia: prediction, risks, proposed management. Obstetrics and Gynecology. 1983; 61(6):715-22.

21. Oral O, Suer N, Karateke A, Duruoz E, Bayat U. Fetal macrosomia. Goztepe Tip Derg. 1991; 6:25-8.

22. Haji-Ebrahim-Tehrani F, Kazemi H, Kordi M. Prevalence and outcome of the macrosomic infants. Acta Medica Iranica. 2007; 45(6):505-9.

23. Weissmann-Brenner A, Simchen MJ, Zilberberg E, Kalter
A, Weisz B, Achiron R, et al. Maternal and neonatal outcomes of macrosomic pregnancies. Maternal and neonatal outcomes of macrosomic pregnancies. Med Sci Monit. 2012; 18(9):77-81.

24. Fuchs F, Bouyer J, Rozenberg P, Senat MV. Adverse maternal outcomes associated with fetal macrosomia: what are the risk factors beyond birth weight? BMC Pregnancy Childbirth.2013; 13:90.

25. Rossi AC, Mullin P, Prefumo F. Prevention, management, and outcomes of macrosomia: a systematic review of literature and meta-analysis. Obstet Gynecol Surv. 2013; 68(10):702-9.

26. Hilden K, Hanson U, Persson M, Fadl H. Overweight and obesity: a remaining problem in women treated for severe gestational diabetes. Diabet Med. 2016; 33(8): 1045-51.

\begin{tabular}{|c|c|c|c|}
\hline \multicolumn{3}{|c}{ AUTHORSHIP AND CONTRIBUTION DECLARATION } \\
\hline Sr. \# & Author-s Full Name & \multicolumn{1}{c}{ Contribution to the paper } & Author=s Signature \\
\hline 1 & Dr. Raheela Rani Junejo & $\begin{array}{l}\text { Contributions to conception } \\
\text { and design acquisition of data, } \\
\text { analysis interpretation of data. } \\
\text { Analysis and interpretaion of } \\
\text { data controbuted in conception } \\
\text { and shares its expert research } \\
\text { opinion. } \\
\text { Drafting the article and shares } \\
\text { its expert research opinion } \\
\text { and experience in finalizing the } \\
\text { manuscript. } \\
\text { Contributed in conception and } \\
\text { interpretation of data and give } \\
\text { his expert view for manuscript } \\
\text { designing. } \\
\text { Drafting the article and shares } \\
\text { its expert research opinion }\end{array}$ \\
\hline 3 & Dr. Rabail Rani Junejo & Prof. Raheel Sikandar \\
\hline 5 & Dr. Shahla Baloch & Dehrunnisa Khaskhe & \\
\hline
\end{tabular}

